\title{
DEVELOPING DESIGN METHODS - A CONCEPTUAL REQUIREMENT FRAMEWORK
}

\author{
Becerril, Lucia (2); Guertler, Matthias (1); Longa, Emmanuel (1,2) \\ 1: University of Technology Sydney; 2: Technical University of Munich
}

\begin{abstract}
Design methods can provide valuable support in structuring and solving complex product design problems. However, the application and the transfer of methods from academia to industry is limited. To date, research has tended to focus on solving this through improved method selection, method adaptation and training. The development of design methods itself has attracted surprisingly low attention. This paper closes this gap and adds a quite new perspective of systematic requirement management of method development. However, the variety of methods, method users and application contexts is a key challenge and does not allow for a universal set of requirements. Thus, this paper transfers the concept of solution-neutral requirements frameworks, which are established in product design, to method development. The framework is derived from analysing and structuring different requirements found in literature. Different requirement sub-/categories allow for accommodating the varying levels of detail of requirements. The framework works like a checklist and helps design researchers to consider the most important requirement categories, which subsequently can be detailed project-specifically.
\end{abstract}

Keywords: Design methods, Requirements, User centred design

\section{Contact:}

Guertler, Matthias

University of Technology Sydney

School of Mechanical and Mechatronic Engineering

Australia

matthias.guertler@uts.edu.au

Cite this article: Becerril, L., Guertler, M., Longa, E. (2019) 'Developing Design Methods - a Conceptual Requirement Framework', in Proceedings of the 22nd International Conference on Engineering Design (ICED19), Delft, The Netherlands, 5-8 August 2019. DOI:10.1017/dsi.2019.152 


\section{INTRODUCTION}

Product designers and engineers are confronted with various challenges when designing new products and services, such as system complexity, technological and market uncertainties, and dynamic customer needs (Gericke et al., 2013; Schuh, 2013). In this paper, we understand 'Design Method' as defined by Pahl et al. (2007) as "systematic, rule-based procedures that help reaching a specific goal in the design process", such as Quality function deployment (QFD) (Hauser and Clausing, 1988) and Brainstorming (Lindemann, 2009). Design Methods can provide important support in tackling and managing these challenges, as proven by empirical studies (e.g. Graner, 2013). Design methods can and need to be adapted to each problem and application context. They provide guidance through their systematic, rule-based and planned approach (Gericke et al., 2016; Lindemann, 2009).

However, despite their benefits, the application of design methods is limited in practice and industry in particular (Tomiyama et al., 2009; Albers et al., 2012; Lindemann, 2016; Gericke et al., 2017). While (engineering) design researchers continuously develop new and innovative design methods, only a minority of them is applied in industry on an ongoing basis (Lopez-Mesa et al., 2004). Although there are examples of successfully applied methods in industry, such as DSM, QFD, and Design Thinking, 'failed' methods are difficult to identify as there is little incentive for researchers to publish such results. Moreover, although methods taught at universities are disseminated trough young professionals to their employing companies (Üreten et al., 2017), practitioners need to update their knowledge continuously (Gericke et al., 2016). This lack of method transfer is also known from neighbouring disciplines, such as the so called "rigour and relevance gap" in management (Fincham and Clark, 2009). Potential reasons are a lack of understanding of benefits and purpose of methods as well as an insufficient adaptability to the specific application context (Eckert and Clarkson, 2005; Albers et al., 2012). Design research has tended to consider this issue primarily from a method communication (e.g. Gericke et al., 2017), adaptation (e.g. Gericke et al., 2013), selection (e.g. Albers et al., 2014; Rothe et al., 2014; Araujo, 2001), and teaching and training (e.g. Bavendiek et al., 2016) perspective.

Although this issue is highly relevant, it is still quite remarkable: if transferred to a product development context, this would mean the purchase and use of a product should be increased by better marketing, better support in choosing it in a retail store and better training how to use it. But would this be the primary way of how a product designer and engineer would approach the design of a new product? The actual development of design methods has only caught limited attention to date. Blessing and Chakrabarti (2009, p. 144) even state that no methodology for developing design methods could be found before 2009 . Existing publications tend to focus on a rather high-level perspective: for instance Braun (2005) analyses the type of methodological support SMEs need, while the "Design Research Methodology (DRM)" (Blessing and Chakrabarti, 2009) and other research methodologies focus rather on WHAT to do rather than HOW to develop a method. Some authors, such as Albers et al. (2018) and Guertler (2018), address this issue but still on a very early stage. A key challenge of development support for design methods is the large variety of methods, method users and application contexts. Since a universal set of method requirements would therefore fail, an alternative approach is needed that combines operational and contingency-based support. Therefore, the resulting research question is: How can design methods be developed systematically to allow for a successful application in industry?

To answer this question, this paper combines established approaches from product requirement management and user-centred approaches. The focus on the method user helps to increase the acceptance and application. Adapting the concept of a solution-neutral requirement checklist (Pahl et al., 2007) allows to create a generic method requirement framework with different sub-/categories of requirements (e.g. ease of use) - but independent from specific requirements (e.g. application effort is lower than two hours). To develop this framework, a literature review is conducted to identify existing scattered advice on method development as well as specific method requirements, which are analysed and clustered to derive the requirement categories. The method requirement framework provides guidance as a quasi-checklist, i.e. engineering design researchers can check if all relevant sub-/categories are covered along with fostering a reflection and discussion why some categories might be left blank.

The remainder of this paper is structured as follows. Section 2 provides an overview of the current research concerning the application of design methods and its barriers. Section 3 describes the research design of this paper. The method development framework is presented in Section 4 and discussed in Section 5. Section 6 concludes the paper and outlines future research activities. 


\section{STATE OF THE ART OF DEVELOPING AND IMPLEMENTING METHODS}

\subsection{Barriers of method application}

Several studies have analysed success factors and barriers of method application over the years (e.g. Albers et al., 2012; Albers et al., 2014; Araujo, 2001; Clarkson and Eckert, 2005; Gericke et al., 2013; Gericke et al., 2017). Badke-Schaub et al. (2011) develop a framework structuring these barriers in performance, presentation and process barriers, which Albers et al. (2012) enhance by an individual and organisation perspective. Exemplary barriers are: difficulties to show the benefits of methods, a lack of integration of methods into company processes, difficulties to learn along with their often too abstract presentation, and a lack of adaptability of methods. A crucial barrier is also an insufficient consideration of method users, such as their individual needs and capabilities and their ways of working and thinking. Braun (2005) also suggests to differentiate between method beginners, experienced users and experts.

\subsection{Method development}

In their work from 2009, Blessing and Chakrabarti (2009, p. 144) state that no methodology for developing design methods and guidelines could be found. Ten years later, this situation has not changed much. Publications on the development of design methods are still limited and usually comprise research methodologies, such as the Design Research Methodology (DRM) (Blessing and Chakrabarti, 2009) and Design Science Research (Kuechler and Vaishnavi, 2008), as well as some early studies. These research methodologies provide guidance in identifying, framing and analysing a practice problem, as well as developing and evaluating methodical support such as methods and tools to solve this problem. However, this guidance is rather high-level since it aims to be applicable in a wide range of research projects. Although, for instance, the DRM provides an exemplary requirement list, this is focussed on s specific type of method but still rather generic. Existing studies tend to focus on specific aspects of developing methods but lack a holistic perspective. For instance, Albers and Schweinberger (2001) identify some specific but limited method development requirements, such as ensure a simple and comprehensible method description, limit theoretical background information to a minimum, consider a potential tool implementation from the beginning, ensure adaptability, and state benefits of a method transparently. On a superordinate level, Braun (2005) investigates, which principal type of methodical support SMEs require depending on different levels of user expertise. Beskow and Ritzén (2000) propose a framework that addresses method implementation from the organizational change perspective and highlight the importance of the method user. Araujo (2001) investigates the acquisition from an industry perspective with a focus on the search and choice processes. Albers et al. (2018) present initial insights of method development in the context of agile approaches and Live Labs, while Becerril et al. (2017) explore influencing factors for user acceptance, which provide a rough orientation but remain rather abstract. Guertler (2018) empirically derive requirements lists of design methods from different industry research projects but leaves the questions of generalisability and prioritisation unanswered.

\subsection{Requirement management in product development}

Blessing and Chakrabarti (2009) stress the similarities between engineering design and engineering design research projects and processes. Key element of each product development project is the analysis and definition of requirements that the product (incl. services, software etc.) must fulfil to solve a specific need or problem. Therefore, literature on engineering design and requirement engineering in particular provide detailed guidance about how to identify, analyse, document, use, manage and update requirements (Pahl et al., 2007; Ulrich and Eppinger, 2008; Lindemann, 2009; Hull et al., 2005). It comprises powerful approaches like stakeholder analyses to identify relevant actors and their interests (Freeman, 2010). Empathic and user-centred approaches like user experience and design thinking (Brown, 2008) allow for revealing underlying tacit needs, which enables more innovative solutions. Acknowledging the existence of software-based requirement and product lifecycle management systems, requirement lists are still a relevant tool to document and manage requirements. To reduce the risk of missing relevant requirements, Pahl et al. (2007) present a checklist that lists the most relevant requirement categories for product development, such as geometry, energy and material (Figure 1).

Along with stating exemplary requirements for each category such as size and heights for geometry, this provides some specific aspects to consider but is still sufficiently generic to be applicable for a large variety of products. 


\begin{tabular}{|ll|}
\hline Main headings & Examples \\
\hline Geometry & $\begin{array}{l}\text { Size, height, breadth, length, diameter, space requirement, } \\
\text { number, arrangement, connection, extension }\end{array}$ \\
Kinematics & $\begin{array}{l}\text { Type of motion, direction of motion, velocity, acceleration } \\
\text { Forces }\end{array}$ \\
& $\begin{array}{l}\text { Direction of force, magnitude of force, frequency, weight, } \\
\text { load, deformation, stiffness, elasticity, inertia forces, resonance }\end{array}$ \\
\hline
\end{tabular}

Figure 1: Section of checklist for setting up a requirement list (Pahl et al., 2007)

\section{RESEARCH DESIGN}

This research is based on a systematic literature review (Booth et al., 2016) on Elsevier's Scopus as established and comprehensive literature data base. Its goal is to identify existing support in developing design methods as well as specifically stated requirements. Due to the relevance of conference publications in engineering design, all types of publications are considered without any time restrictions. The search terms in title, abstract and keywords cover a wide range of design and innovation methods, methodologies, support, techniques and instruments with a focus on industry, companies, firms and practice in general. The search scope is limited to their adoption, application, application, transfer, selection, acceptance, implementation and uptake.

The identified 144 publications are filtered, excluding those not related to the research question or in languages other than English. The resulting 75 publications are analysed in detail to extract a list with different method development requirements. This broad range of requirements with varying levels of abstraction are clustered in sub-/ categories following a bottom-up approach. The underlying intention is the development of a method requirement framework similar to the one for product design (Pahl et al., 2007) but providing more structure by considering different levels of requirement sub-/categories. The framework is also enhanced by aspects from technology acceptance models, communication theory, product development, and user experience (UX) to provide additional support. The framework is initially evaluated through discussions with two experienced engineering design researchers concerning the general setup and structure of the framework and its alignment with the experience from previous industry research projects of the researchers. A revised version of the framework incorporates their feedback along with pointing out open gaps, limitations and future research steps.

\section{METHOD DEVELOPMENT REQUIREMENT FRAMEWORK}

The method development requirement (MDR) framework aims at supporting method developers in the early phases of method design to define a complete set of requirements and to avoid common barriers and pitfalls in method application and transfer. The framework does not aim to provide a "one-fits-all" requirement list but to support in defining problem-specific requirements. The MDR is based on 113 requirements identified from the literature analysis (cf. Section 3). The development of the MDR included a bottom-up and a top-down approach to ensure a systematic and holistic setup. First, using a step-wise bottom-up approach, the requirements were clustered into requirement categories of three different abstraction levels. Second, using a top-down approach, these clusters were refined and structured by analysing exiting requirement frameworks as well as technology acceptance models, communication theory, product development and user experience (UX) frameworks.

The MDR framework is shown in Figure 2: Aside from the (B) Method development requirement sub-/categories, the MDR framework also comprises two additional elements: (A) Superordinate method development principles, which comprise superordinate design strategies that affect a multitude of different requirement categories; and (C) Supporting activities, which are not directly linked to the actual design of a method but are important for the subsequent method implementation in a company.

\subsection{Superordinate method development principles}

The analysis of requirements also revealed some overarching aspects that are important for method development, cannot be linked to a single requirement category but affect a wide of them. In this respect, they are similar to design principles (Lindemann, 2009) and describe general strategies of method development. The hitherto identified method development principles are: 
- Considering user expertise level: the experience of using design methods (inexperienced, experienced, and expert) influences the usage, goals, and the functionalities and design of a method.

- Ensuring positive cost-benefit ratio: to provide real impact and value-add, a method is not an end in itself but has to generate greater benefits than the effort and resources it consumes.

\section{A: Superordinate method development principles}

\section{B: Method development requirement categories}

\begin{tabular}{|c|c|c|}
\hline Level 2 & Level 3 (excerpt) & Exemplary requirements (excerpt) \\
\hline \multicolumn{3}{|c|}{ 1) Usability and User Experience (Level 1) } \\
\hline \multirow{2}{*}{ 1.1. Ease of Use } & Ease of interaction & Degree of prescription, complexity of steps, etc. \\
\hline & Autonomy in method use & Solo or team-based methods, need for specialist assistance, etc. \\
\hline 1.2. Understandability & $\ldots$ & $\ldots$ \\
\hline 1.3. Learnability & $\ldots$ & $\ldots$ \\
\hline 1.4. Desirability & $\ldots$ & $\ldots$ \\
\hline \multicolumn{3}{|l|}{ 2) Utility and Performance (Level 1) } \\
\hline \multirow{4}{*}{$\begin{array}{l}\text { 2.2. Dem onstrability of } \\
\text { results }\end{array}$} & $\ldots$ & $\ldots$ \\
\hline & Transparency of results & Documentation of method application process, etc. \\
\hline & Traceability of results & Track results with metrics and KPIs, etc. \\
\hline & Result frequency & Present intermediate term results, produce results in a timely basis, etc. \\
\hline 2.3. Reliability & $\ldots$ & $\ldots$ \\
\hline \multicolumn{3}{|l|}{ 3) Industrial Fitness (Level 1) } \\
\hline \multirow{5}{*}{ 3.2. Compatibility } & $\ldots$ & $\ldots$ \\
\hline & $\underline{\text { Strategic Fit }}$ & Business model, compliance, design strategy, etc. \\
\hline & Organisational Fit & Company culture, management style, work environment, team, etc. \\
\hline & Process Fit & Production system, project, product development stage, etc. \\
\hline & Method Fit & Method coupling, etc. \\
\hline 3.3. Versatility & $\ldots$ & $\ldots$ \\
\hline
\end{tabular}

Figure 2: Method development requirement framework (excerpt)

\subsection{Method development requirement categories}

Figure 2 shows the MDR framework and its three top-level requirement categories. Blessing and Chakrabarti (2009) suggest two objectives for the evaluation of methods in engineering design: identifying whether (1) a method developed can be used for the task for which it is intended for (i.e. the method is applicable) and (2) the method actually contributes to the success of the task's goals. The MDR framework focuses on the applicability and success of the method through all method design phases, which is reflected in two of the three main requirement categories: 1) Usability and User Experience: describing aspects of ease of use and of learning a new method; and 2) Utility and Performance: addressing the functionality and trustworthiness of methods and outcomes. To address the challenges and barriers of transferring a new method from academia to industry, the third category 3) Industrial Fitness defines how well a method fits and can be tailored to a given application context.

These three Level 1 categories are further detailed in sub-categories as described in the following.

\subsubsection{Usability and User Experience requirements}

The requirement category Usability and User Experience encompasses requirements that ensure that the method users are able and motivated to apply the method.

The requirements within the sub-part Usability ensure that the method can be used for the intended task. According to the ISO 9241-110 (2006), usability is the "extent to which a product or system can be used by specified users to achieve specified goals with effectiveness, efficiency, and satisfaction in a specified context of use". Nielsen (2010) lists usability as a key factors for system acceptance, which is achieved when the system is easy to learn, efficient to use, easy to remember, subjectively pleasing, and allows fewer errors. The ISO 25010 describes usability in the context of software products similarly, including aspects such as recognisability, learnability, operability, user error protection, user 
interface aesthetics, and accessibility. Based on the usability components from existing frameworks and the requirements categories identified in the bottom-up approach, the MDR Framework clusters requirements concerning method usability into three groups: "Ease of Use", "Understandability", and "Learnability".

1.1. Ease of Use addresses frequent complaints of practitioners that methods are too complex (Becerril et al., 2017) or difficult to apply (Renzi et al., 2015). Ease of Use is a measurement of how easy it is for the user to apply the method and comprises two Level 3 requirement subcategories: "ease of interaction" and "autonomy of method use". Ease of interaction includes, for example, the number of steps and the complexity of each of this step. Some methods, such as brainstorming, comprise only a few steps while in others, such as Quality Function Deployment, have several phases and steps. Requirements in this category consider the needs of different method users. "Autonomy of method use" ensures that the method can be applied autonomously by an individual or group of method users. An exemplary requirement in this category could address the potential need for an external facilitator.

In addition, usability is highly influenced by whether the user experiences the method as understandable. To apply a method successfully, the user needs to understand whether the method itself and its components are suitable, which functions it delivers and how the method can be executed in a specified context of use (ISO/IEC 25010, 2011; Heinrich, 2014).

In method design, 1.2. Understandability is achieved through a sufficient method description, presentation and documentation this includes for example the use of proper language, use of illustrations or examples of application.

Derived from software development, 1.3. Learnability describes how easy it is for a user to learn to use a method. According to Blessing and Chakrabarti (2009) learnability is the ease with which novice users can acquire competent performance. Requirements included in the learnability category are for example maximum number of attempts before the user can apply the method independently.

The second sub-aspect of this category, User Experience (UX), focuses on creating experiences rather than preventing usability problems (Hassenzahl and Tractinsky, 2006). By creating positive experiences, for example through gamification, method developers can increase user motivation and acceptance of the method (Nielsen, 2010). This can also help to prevent barriers regarding usability. User experience design is the process of enhancing the hedonic, affective or experiential aspects of technology use (Hassenzahl and Tractinsky, 2006). In a first step towards integrating UX approaches to method design, the MDR Framework includes the requirement sub-category of Desirability. 1.4. Desirability combines two dimensions of user experience: hedonic quality and visual attractiveness (Mahlke, 2002).

\subsubsection{Utility and performance requirements}

This type of requirements ensure that a method suits method users to achieve individual and company goals. Badke-Schaub et al. (2011) highlight barriers concerning method performance including missing validation. Performance-related requirements ensure that applying design methods results in an improved design performance, e.g. reduced time to market or increased customer satisfaction. Some barriers regarding method acceptance derive from the lack of (perceived) utility as practitioners are often unaware of the benefits of applying specific design methods (Reiß et al., 2017).

2.1. Functional Suitability is derived from the ISO/IEC 25010 (2011) and defines the degree to which a method provides functionalities that meet stated and implied user needs when used under specified conditions. This can include aspects, such as support of a concrete activity in the development process or a specific improvement to time to market.

A central aspect of method acceptance is users trust a method can support their work. Thus, the 2.2. Demonstrability of Results plays an important role in the decision for or against using a particular method. In addition, a method needs to demonstrate a short and long-term contribution to the method users, the company and other stakeholders (López-Mesa and Bylund, 2011). Therefore, requirements of "transparency of results" and "traceability of results" ensure that intermediate and final outcomes of a method can be clearly stated as well as clearly be traced back to specific inputs, activities and decisions. Exemplary requirements could be KPIs, which indicate the performance of the method and allow for controlling (e.g. number of generated ideas) (Guertler, 2018). Moreover, a common barrier is that the benefits are not realised immediately (López-Mesa and Bylund, 2011). Proving the benefit of a method is particularly challenging when benefits appear in later stages of the project or even in a following project (Gericke et al., 2017). Therefore, the "result frequency" requirements address the importance of explicitly defining a schedule for analysing and documenting intermediate results. 
The third sub-category, 2.3. Reliability has two components: "Internal reliability" (verification) focuses on the accuracy, consistency and robustness of method results. Hence, it ensures that an identical input and iterative application of a method lead to similar or identical results (Guertler, 2018). It also helps to prove method benefits, which is crucial for their acceptance in companies (Jagtap et al., 2014). "External reliability" (validation) requirements ensure that method outcomes create actual benefits in practice.

\subsubsection{Industrial fitness requirements}

As discussed, several challenges arise when transferring methods from academic pilot applications to daily practice in industry, which requires that a new method is compatible with existent company processes and systems. A method might provide a great user experience and results, but if it cannot be implemented in practice, its features become irrelevant. Industrial Fitness focuses on method characteristics, which affect ability of a method to be implemented in an industrial context - ranging from its fit to a specific context to a broader range of application contexts like companies and projects.

A central aspect is 3.1. Required Resources as companies often complain about a lack of necessary resources to learn, implement and use new methods and tools (Reiß et al., 2017). Along with this, methods developed in academia sometimes require resources (e.g. information) that are not (easily) available in each company (Jagtap et al., 2014). This requirement subcategory support in aligning necessary and actually available resources (e.g. time, software, knowledge).

3.2. Compatibility requirements ensure the general alignment of a method and the characteristics of a focal company. They can be differentiated in requirements concerning the "strategic fit", such as the alignment to a company's business model and design strategy; "organisational fit" to e.g. company culture or management style; "process fit" to e.g. a specific production system or project; and "methods fit" such as coupling with existing methods.

Jagtap et al. (2014) argue that it is necessary to adapt new methods to the needs of a company rather than developing generic methods for a wide range of products and users. However, this adaptation is often done intuitively with suboptimal results. The sub-category 3.3. Versatility comprises requirements that ensure a systematic adaptability of design methods, such as modularisation or expandability aspects. They also provide guidance on how to tailor the method to specific needs.

\subsection{Supporting activities}

In addition, several requirements that cannot be addressed though method design resulted from the literature survey, such as "Methods need to be made available to the users through different channels. These requirements are relevant for the method designer since they address common pitfalls of method acceptance and adoption. Nevertheless, they are not linked to properties or features of the method and are thus outside the intended scope for the requirement categories. Therefore, we propose supporting activities that address these requirements. Supporting activities, are activities recommended during the method development process. They can be performed once or repeatedly across the method design. The framework includes following supporting activities: Manage method stakeholders, Plan support for method adoption, and Ensure method-user-centred design of methods.

\subsection{Using the MDR framework}

The method development requirement framework provides guidance as a quasi-checklist of relevant requirements categories similar to checklist from product design (Pahl et al., 2007). As a first step, the method users and stakeholders shall be identified. Stakeholder analysis, user segmentation or personas support developing requirements from different perspectives for the different method users or application scenarios.

Then, the method developer shall discuss and derive their own specific requirements for each of the subcategories. The formulated requirements should be solution-neutral, specific and can be qualitative or quantitative. Exemplary requirements are shown Table 1.

Method stakeholders can be involved in this stage as well. If a sub-category is not relevant for the method being developed, we recommend to explicitly documenting the reason. This a) fosters discussion regarding why this category shall be left blank and b) allows to revisit these categories in the future. The requirements can then be structured according to the higher-level categories. Furthermore, we recommend the method developer to ratify that the formulated requirements are consistent with the design principles and the overall method goals. 
Table 1: Requirements examples for a creativity method

\begin{tabular}{|l|ll|}
\hline Resources & $\bullet$ & $\begin{array}{l}\text { The application of the creativity method shall require a maximum of } 20 \text { person- } \\
\text { hours } \\
\text { The method application shall exclusively use standard workshop materials (post- } \\
\text { its, etc.) }\end{array}$ \\
\hline Understandability & $\bullet$ & Key terminology shall be clarified beforehand \\
\hline Compatibility & $\bullet$ & The method shall be able to include team members who work remotely \\
\hline
\end{tabular}

\section{Discussion}

To date, the development of methods has only attracted limited attention in academic research. A key challenge is the impossibility of defining a universal set of requirements due to the large variety of different methods, users and application contexts. To overcome this gap and challenge, this paper moves a step higher and develops a "Method Development Requirement Framework" through adapting the concept of requirement checklists from product design (Pahl et al., 2007). The different sub-/categories of requirements function as a structured checklist and help design researchers to navigate through the development process of new design methods. It fosters reflection and discussion about each sub-/ category. Relevant ones can be detailed with problem-specific requirements, while irrelevant sub-/ categories can be ignored. "User experience" as one of the three top-level categories highlights the importance of humans as actual users of a method similar to human-centred approaches in product design. In this respect, it is an extended perspective of Albers et al. (2012) "individual" dimension. The framework also comprises superordinate method development principles, which are crucial but cannot be linked to single requirements, such as a positive cost-benefit ratio. "Supporting activities" are not linked to the design of a method itself but to the subsequent method implementation in a company.

Despite a systematic research design, this research shows several limitations. Although carefully identified, literature might not be comprehensive due to the broad variety of synonym terms for design methods. Another issue of using case studies is their usual focus on successful projects, which does not allow for analysing the requirements and development process of unsuccessful methods. A general limitation is the conceptual character of this research. Applying and evaluating the requirement framework in industry research projects is crucial to test its validity and benefits. This is also important to explore whether the framework allows for a general use or it needs to be adapted for different types of design methods, such as creativity and assessment methods. Along with investigating dependencies between requirements and requirement categories, a potential prioritisation of them must be analysed, i.e. which are essential, and which are rather optional.

\section{CONCLUSION AND NEXT STEPS}

Methods can provide great benefits as studies like Graner (2013) have proven. Nevertheless, their transfer from academia to practice and particularly their application in industry is limited. This paper enhances existing research on method communication, selection, training and implementation by adding a surprisingly underutilised perspective: the systematic development of design methods. Since the large variety of methods, method users and application contexts does not allow for universal requirements lists, this paper develops and presents a solution-neutral requirement framework for developing design methods. Building on adapted requirement frameworks from product requirement management (Pahl et al., 2007), it works like a quasi-checklist that ensures engineering design researchers consider all relevant requirement categories when developing design methods. The particular requirements within each category are defined problem- und project-specifically. Including aspects of user-centred approaches into this framework ensures a user and application focussed method development.

This paper contributes to existing research by providing an additional perspective, i.e. the development of design methods. The presented insights into method development provide a better understanding of different method types and application contexts. Design researchers particularly benefit by the presented method requirement framework, which offers operational user-centred guidance for developing design methods. This also contributes to existing research methodologies like the Design Research Methodology, which usually tend to describe WHAT to do, by adding more details around $H O W$ to develop design methods. Industry and practice in general will benefit by new design methods, which better fit to the needs of their method users and organisational boundary conditions. In the long- 
run, an increased transfer and application of design methods in companies can, for instance, help to strengthen their innovativeness and competitiveness. In addition, the presented approach can help develop improvement measures for existing methods by identifying unaddressed requirement categories.

This paper represents an initial step of a larger research program. An essential following step will be the practical application and evaluation of the presented conceptual framework in a research project. First insights in the context of a current $\mathrm{PhD}$ project look promising but require more careful evaluation and analysis. Along with the general applicability of the framework, its comprehensibility needs to be explored - specifically if requirement sub-/categories are missing or if categories can be combined. This also includes the analysis of interdependencies between categories as well as dependencies to specific types of design methods. In addition, questions around prioritisation of requirements and requirement categories need to be investigated. To allow easy access to a future version of the method requirement framework, it should also be explored how it might be implemented in existing research methodologies. In parallel, it would necessary to investigate the long-term success of new design methods beyond a usually only shortterm oriented evaluation. Especially cases of unsuccessful design methods bear the potential for particularly valuable insights but are normally underrepresented in literature.

\section{REFERENCES}

Albers, A., Bursac, N., Eckert, C.M., Walter, B., Wilmsen, M. and Heimicke, J. (2018), "Agile Product Development: A Live-Lab Case Study on Product Properties for Proces Planning", paper presented at 15th International Design Conference, May, 21-24, 2018, Dubrovnik. https://doi.org/10.21278/idc.2018.0341.

Albers, A., Lohmeyer, Q. and Radimersky, A. (2012), "Individuelle und organisatorische Akzeptanz von Methoden des Systems Engineering", paper presented at Tag des Systems Engineering 2012, 07.09.11.2012, Paderborn, Germany.

Albers, A., Reiß, N., Bursac, N., Urbanec, J. and Lüdcke, R. (2014), "Situation-appropriate method selection in product development process - Empirical study of method application", paper presented at NordDesign 2014, 27.-29.08.2014, Espoo, Finland / Melbourne, Australia.

Albers, A. and Schweinberger, D. (2001), "Methodik in der praktischen Produktentwicklung - Herausforderung und Grenzen", in Spath, D. (Ed.), Vom Markt zum Produkt: Impulse für die Innovationen von morgen, LOGX-Verl., Stuttgart, pp. 1-9.

Badke-Schaub, P., Jaap, D. and Roozenburg, N. (2011), “Towards a Designer-Centred Methodology: Descriptive Considerations and Prescriptive Reflections", in Birkhofer, H. (Ed.), The future of design methodology, Springer, London, New York, pp. 181-197. https://doi.org/10.1007/978-0-85729-615-3_16.

Bavendiek, A.-K., Inkermann, D. and Vietor, T. (2016), "Teaching design methods with the interactive 'Methodos' portal', paper presented at The 14th International Design Conference: DESIGN 2016, 16.19.05.2016, Cavtat, Dubrovnik, Croatia.

Becerril, L., Hollauer, C., Kattner, N., Weidmann, D. and Lindemann, U. (2017), "How to assess the acceptability of design support", in Schulze, S.-O., Tschirner, C., Kaffenberger, R. and Ackva, S. (Eds.), Tag des Systems Engineering: Paderborn, 8. -10. November 2017, Carl Hanser Verlag GmbH \& Co. KG, München, pp. 217-228.

Blessing, L.T.M. and Chakrabarti, A. (2009), DRM, a Design Research Methodology, Springer, Heidelberg.

Booth, A., Sutton, A. and Papaioannou, D. (2016), Systematic approaches to a successful literature review, Second edition, SAGE, Los Angeles, London, New Delhi.

Braun, T.E. (2005), Methodische Unterstützung der strategischen Produktplanung in einem mittelständisch geprägten Umfeld, Dissertation, Tehnical University of Munich (TUM), 1. Aufl., Dr. Hut, München.

Brown, T. (2008), "Design Thinking", Harvard Business Review, Vol.86 No.6, pp. 84-92.

Clarkson, J. and Eckert, C.M. (Eds.) (2005), Design process improvement: A review of current practice, Springer, London.

Eckert, C.M. and Clarkson, J. (2005), "Design Process Improvement A review of current practice", in Clarkson, J. and Eckert, C.M. (Eds.), Design process improvement: A review of current practice, Springer, London, pp. 1-29.

Fincham, R. and Clark, T. (2009), "Introduction: Can We Bridge the Rigour-Relevance Gap?", Journal of Management Studies, Vol. 46 No. 3, pp. 510-515. https://doi.org/10.1111/j.1467-6486.2009.00834.x.

Freeman, R.E. (2010), Strategic Management: A Stakeholder Approach, Cambridge University Press, Cambridge, MA, USA.

Gericke, K., Eckert, C.M. and Stacey, M. (2017), “What do we need to say about a design method?", paper presented at 21st International Conference on Engineering Design (ICED 17), 21.-25.08.2017, Vancouver, Canada. 
Gericke, K., Kramer, J. and Roschuni, C. (2016), “An Exploratory Study of the Discovery and Selection of Design Methods in Practice”, Journal of Mechanical Design, Vol. 138 No. 10, pp. 1-10. https://doi.org/10.1115/1.4034088.

Gericke, K., Meißner, M. and Paetzold, K. (2013), "Understanding the Context of Product Development", paper presented at DS 75-3: Proceedings of the 19th International Conference on Engineering Design (ICED13), 19.-22.08.2013, Seoul, Korea.

Graner, M. (Ed.) (2013), Der Einsatz von Methoden in Produktentwicklungsprojekten: Eine empirische Untersuchung der Rahmenbedingungen und Auswirkungen, Springer Gabler, Wiesbaden.

Guertler, M.R. (2018), "How to Design Methods for Application - Empirical Insights from Industry", paper presented at 15th International Design Conference, May, 21-24, 2018, Dubrovnik. https://doi.org/10.21278/idc.2018.0169.

Hassenzahl, M. and Tractinsky, N. (2006), "User experience - a research agenda", Behaviour \& Information Technology, Vol. 25 No. 2, pp. 91-97. https://doi.org/10.1080/01449290500330331.

Heinrich, R. (2014), "Business Process Quality”, in Heinrich, R. (Ed.), Aligning Business Processes and Information Systems, Springer Fachmedien Wiesbaden, Wiesbaden, pp. 21-57. https://doi.org/10.1007/978-3-658-06518-8_3.

Hull, E., Jackson, K. and Dick, J. (2005), Requirements engineering, 2nd ed., Springer, London.

ISO 9241-110 (2006), "Ergonomics of human-system interaction -- Part 110: Dialogue principles No. 9241110 ".

ISO/IEC 25010 (2011), "Systems and software engineering -- Systems and software Quality Requirements and Evaluation (SQuaRE) -- System and software quality models No. 25010”.

Jagtap, S., Warell, A., Hiort, V., Motte, D. and Larsson, A. (2014), "Design methods and factors influencing their uptake in product development companies ", paper presented at DS 77: Proceedings of the 13th International Design Conference DESIGN 2014, 19.-22.05.2014, Dubrovnik, Croatia.

Kuechler, B. and Vaishnavi, V. (2008), "On theory development in design science research. Anatomy of a research project”, European Journal of Information Systems, Vol. 17 No. 5, pp. 489-504. https://doi.org/10.1057/ejis.2008.40.

Lindemann, U. (2009), Methodische Entwicklung technischer Produkte: Methoden flexibel und situationsgerecht anwenden, VDI-Buch, Springer, Berlin, Germany.

Lindemann, U. (2016), "Methoden in der Produktentwicklung”, in Lindemann, U. (Ed.), Handbuch Produktentwicklung, Carl Hanser, Munich, Germany, pp. 623-628. https://doi.org/10.3139/9783446445819.021.

Lopez-Mesa, B., Eriksson, S. and Thompson, G. (2004), "The decomposition and linkage of design methods and problems", paper presented at 6th Design Structure Matrices (DSM) International Workshop, 12.14.09.2004, Cambridge, UK.

López-Mesa, B. and Bylund, N. (2011), "A study of the use of concept selection methods from inside a company", Research in Engineering Design, Vol. 22 No. 1, pp. 7-27. https://doi.org/10.1007/s00163-0100093-2.

Mahlke, S. (2002), "Factors influencing the experience of website usage", in Terveen, L. and Wixon, D. (Eds.), CHI '02 extended abstracts on Human factors in computing systems - CHI '02, Minneapolis, Minnesota, USA, 20/04/2002 - 25/04/2002, ACM Press, New York, New York, USA, p. 846. https://doi.org/10.1145/506443.506628.

Nielsen, J. (2010), Usability engineering, 18th ed., Morgan Kaufmann Publishers, Amsterdam.

Pahl, G., Beitz, W., Blessing, L., Feldhusen, J., Grote, K.-H. and Wallace, K. (Eds.) (2007), Engineering Design - A systematic approach, 3rd, Springer London, London, UK.

Reiß, N., Albers, A. and Bursac, N. (2017), "Approaches to increasing method acceptance in agile product development processes", paper presented at 21 st International Conference on Engineering Design (ICED 17), 21.-25.08.2017, Vancouver, Canada.

Renzi, C., Leali, F., Pellicciari, M., Andrisano, A.O. and Berselli, G. (2015), "Selecting alternatives in the conceptual design phase. An application of Fuzzy-AHP and Pugh's Controlled Convergence", International Journal on Interactive Design and Manufacturing (IJIDeM), Vol. 9 No. 1, pp. 1-17. https://doi.org/10.1007/s12008-013-0187-y.

Rothe, M., Damerau, T., Schmölders, M., Körper, C., Jochem, R. and Stark, R. (2014), “Open Innovation-Erfolg mit der richtigen Methodenwahl”, Zeitschrift für wirtschaftlichen Fabrikbetrieb, Vol. 109 No. 4, pp. 250256.

Schuh, G. (2013), Lean Innovation, VDI-Buch, Springer Vieweg, Berlin, Germany.

Tomiyama, T., Gu, P., Jin, Y., Lutters, D., Kind, C. and Kimura, F. (2009), "Design methodologies. Industrial and educational applications", CIRP Annals - Manufacturing Technology, Vol. 58 No. 2, pp. 543-565. https://doi.org/10.1016/j.cirp.2009.09.003.

Ulrich, K.T. and Eppinger, S.D. (2008), Product design and development, 4th, McGraw-Hill Higher Education, Boston, MA, USA. 